\title{
A revolução leitora entre os séculos XX e XXI e os atratores visuais de Frida
}

\section{Kahlo}

DOI: https://doi.org/10.22409/pragmatizes.v12i22.51368

\section{Mariane Rocha Silveira ${ }^{1}$ Ivânia Campigotto Aquino ${ }^{2}$}

\begin{abstract}
Resumo: $O$ presente artigo científico, de caráter qualitativo e descritivo, tem como objetivos principais apresentar um recorte sobre o contexto histórico-social, a vida e a obra da artista mexicana Frida Kahlo, assim como realizar uma análise dos elementos visuais que atraíram diferentes leitores a partir de uma perspectiva teórica distinta da fortuna crítica que ora se apresenta sobre a pintora. Para isso, conta-se, como fundamentação teórica, com os estudos de Canevacci (2008), em relação aos atratores visuais, e de Santaella $(2004,2013)$, que colabora por meio da definição quanto aos tipos de leitores que se desdobram entre os séculos XX e XXI. Para a reconstrução histórica do México e da biografia de Frida, o estudo baseia-se nas produções de Fernández (2002), Florencio (2014), Henestrosa (2012), Herrera (2011), Kettenmann (2015) e Zamora (2007). Os resultados parciais, já que o estudo se encontra em andamento, apontam que Frida Kahlo, como bodyspace, criou um dress-code, ou seja, um estilo próprio com base em suas raízes histórico-sociais e em sua location; e, com isso, atraiu os olhares daqueles que não estavam acostumados à semiótica impressa por ela.
\end{abstract}

Palavras-chave: Atratores visuais; leitor óptico; Frida Kahlo; México.

\section{La revolución lectora entre los siglos XX y XXI y los atractores visuales de Frida Kahlo}

Resumen: Este artículo científico, de enfoque cualitativo y descriptivo, tiene como principales objetivos presentar un panorama sobre el contexto histórico-social, la vida y la obra de la artista mexicana Frida Kahlo, así como realizar un análisis de los elementos visuales que han atraído diferentes lectores desde una perspectiva teórica distinta a la fortuna crítica que ahora se presenta sobre la pintora. Para ello, como fundamentación teórica, se apoya en los estudios de Canevacci (2008), con relación a los atractores visuales, y de Santaella $(2004,2013)$, que contribuye a través de la definición sobre los tipos de lectores que se desarrollan entre los siglos XX y XXI. Para la reconstrucción histórica de México y de la biografía de Frida, el estudio toma como base las producciones de Fernández (2002), Florencio (2014), Henestrosa (2012), Herrera (2011), Kettenmann (2015) y Zamora (2007). Los resultados parciales, ya que el estudio se encuentra en curso, apuntan que Frida, como bodyspace, ha creado un dress-code, o sea, un estilo propio con base en sus raíces histórico-sociales y en su location; y, con ello, ha atraído las miradas de aquellos que no estaban acostumbrados a la semiótica impresa por ella.

Palabras clave: Atractores visuales; lector óptico; Frida Kahlo; México.

\footnotetext{
${ }^{1}$ Mariane Rocha Silveira. Doutoranda em Letras pela Universidade de Passo Fundo (UPF), RS, Brasil. E-mail: marianesilveira@upf.br - https://orcid.org/0000-0002-2462-4876

${ }^{2}$ Ivânia Campigotto Aquino. Doutora em Letras - Estudos de Literatura pela Universidade Federal do Rio Grande do Sul. Professora Titular III da Universidade de Passo Fundo, Rio Grande do Sul, Brasil. E-mail: ivania@upf.br - https://orcid.org/0000-0001-9221-3473.
} 
The reading revolution between the twentieth and twenty-first centuries and Frida Kahlo's visual attractors

Abstract: This qualitative, descriptive paper is aimed at presenting a review of the socio-historic context, life and work of Mexican artist Frida Kahlo, as well as carrying out an analysis of the visual elements that attracted different readers from a theoretical viewpoint different from the critical appraisal presently given to the painter. To reach those aims, the theoretical framework was drawn from studies by Canevacci (2008), concerning visual attractors, and Santaella (2004, 2013), who provides definitions of the types of readers existing between the twentieth and the twenty-first centuries. For the reconstruction of Mexican history and Frida's biography, the study draws on works by Fernández (2002), Florencio (2014), Henestrosa (2012), Herrera (2011), Kettenmann (2015) and Zamora (2007). Partial results, as the study is still in progress, suggest that Frida Kahlo, as a bodyspace, created a dress-code, a unique style based on her socio historical background and on her location; and, by doing so, she attracted eyes that were not used to the semiotics she printed.

Keywords: Visual attractors; optical reader; Frida Kahlo; Mexico.

\section{A revolução leitora entre os séculos $X X$ e XXI e os atratores visuais de Frida}

\section{Kahlo}

\section{Introdução}

Em meio a pessoas vestidas de forma sóbria e tradicional, ela se destaca. Não por uma beleza extraordinária, mas porque se fez bela em sua atitude estética deliberadamente deslocada dos padrões reguladores da moda. Saia de corte reto, de veludo ou de algodão com babado na barra. Blusão multicolorido e com bordados únicos feitos à mão. Para acompanhar, muitas joias: longos colares, brincos de tamanho expressivo e numerosos anéis. Muitos desses adereços feitos da mais original prata mexicana e de pedras pré-colombianas. Como um imã, ela magnetiza olhares e cativa antes mesmo de se manifestar; afinal, ostenta uma imagem genuína e atratora. Seu corpo, maculado por dores, torna-se uma espécie de atrator, como um suporte de toda uma beleza singular, mesmo injuriado pelo destino.

Eis Frida Kahlo, a mulher que marcou época por sua atitude artística e revolucionária. A arte não se manifestava apenas em seus retratos e autorretratos, mas também em seu corpo, em sua casa e, inclusive, em seus posicionamentos - uma mulher única e além de seu tempo. Como ninguém, ela soube enfrentar - à sua maneira - as dores impingidas pela vida e mesclar a cultura indígena 
tehuana - herança de sua mãe e sua identidade - com o contemporâneo, fazendo-se ela própria uma manifestação artística sem igual, um corpo atrator expandido histórica e culturalmente.

Essas sucintas informações a respeito de uma das mais expressivas artistas do século $X X$ ajudam a esclarecer o que pretendemos no presente estudo: apresentar um recorte sobre o contexto históricosocial, a vida e a obra da artista mexicana Frida Kahlo, assim como realizar uma análise dos elementos visuais que atraíram diferentes leitores sob uma ótica diferente daquela abordada por vários estudos acerca da pintora mexicana. Para tanto, buscamos refletir sobre o porquê de Frida Kahlo atrair tantos olhares enquanto ainda viva e, mesmo após 47 anos de seu falecimento, atrair tantos leitores de sua história e de sua criação artística. O que a torna diferente ou especial? E, muito importante, que leitor é esse que segue admirando-a? Para responder a essas questões, delineamos um percurso histórico-bibliográfico, o qual apresentamos brevemente.
Em primeiro lugar, realizamos um panorama teórico sobre os tipos de leitores, fundamentado nas considerações de Lucia Santaella (2004, 2013), bem como sobre os fetichismos e os atratores visuais, com base nos pressupostos de Massimo Canevacci (2008). Após, traçamos uma concisa exposição com relação ao contexto histórico-social em que Frida Kahlo viveu e sobre sua vida pessoal. Para isso, contamos com o aporte de Fernández (2002), Florencio (2014), Herrera (2011), Kettenmann (2015) e Zamora (2007). E, finalmente, expomos a análise a respeito dos atratores visuais de Frida Kahlo, uma calcificação histórica-social dividida entre os séculos XX e XXI.

\section{Entrelaçamentos teóricos}

Nesta seção, elucidamos os princípios teóricos que sustentam nossa análise. Um dos enfoques observa os estudos da escritora Lucia Santaella $(2004,2013)$ no tocante aos constructos leitores, sobretudo quanto às definições dos tipos de leitores estabelecidos por ela e definidos conforme as tecnologias com as quais cada leitor teve contato em sua época. Nessa parte, ainda, ensaiamos outra 
definição sobre um tipo de leitor que Canevacci (2008) cita em sua obra, mas que ousamos mesclar com os leitores do século XXI apontados por Santaella. O esquadrinhamento a respeito deste leitor aparecerá, sobretudo, na última seção do artigo, destinada à análise em si.

De maneira consoante, apresentamos os princípios teóricos que emergem das pesquisas de Massimo Canevacci (2008) quanto aos atratores visuais, descompactados em três outras conceituações também essenciais para a análise: bodyscape, location e dress-code. Eles aparecem ora em interseção, ora em justaposição, mas sempre muito próximos, porque juntos representam a atração visual que defendemos. Isso posto, desenrolamos a fundamentação teórica.

\section{Breve percurso de leitores e um} novo caminho de leitura

Com o passar do tempo e com as consequentes inovações tecnológicas, as leituras e os leitores se transformaram. No início da era pré-industrial, existia o leitor do livro impresso, das imagens fixas e expositivas. Referimo-nos, aqui, ao leitor contemplativo, que começava a ler para si próprio devido à instauração do silêncio nas bibliotecas durante a Idade Média. Assim, aos poucos, as palavras passaram a ocupar o espaço interior.

Mais tarde, como resultado da Revolução Industrial, surgiu o leitor movente, o "leitor do mundo em movimento, dinâmico, mundo híbrido" (SANTAELLA, 2004, p. 19). Um leitor que assistiu à "explosão do jornal", das novas eras da eletrônica, da ascensão da fotografia, do surgimento da televisão, e que teve sua própria vida modificada. Naquele ínterim, tudo passou a estar envolto por imagens que fascinavam aqueles que as viam, que eram reproduzidas e substituídas por outras mais atraentes, incessantemente, como marca do consumismo da época: "a vida cotidiana passou a ser um espectro visual, um desfile de aparências fugidias, um jogo de imagens que hipnotizam e seduzem" (SANTAELLA, 2004, p. 28).

Com a ascensão do mundo virtual, no início do século $\mathrm{XXI}$, a sociedade de modo geral sofreu transformações com relação a seus comportamentos e sua visão de 
mundo. Essa sociedade, em um novo traçado cultural, em rede e digital, inaugura-se e envolve até os sujeitos que não possuíam internet em suas residências, mas que usavam variados serviços, como bancos e caixas de autoatendimento ou home bankings. Além disso, não foi necessário um grande período para que clientes passassem a usar um celular com várias funções tecnológicas; eleitores passassem a eleger por voto eletrônico; pessoas começassem a se comunicar em um mundo dirigido cada vez mais pela interação entre homem e máquina. $E$, através desse novo universo, surgiu um outro tipo de leitor, na denominação de Santaella (2004, p. 33), o leitor imersivo, o qual

[...] navega numa tela, programando leituras, num universo de signos evanescentes eternamente disponíveis, contanto que não se perca a rota que leva a eles. Não é mais tampouco um leitor contemplativo que segue as sequências de um texto, virando páginas, manuseando volumes, percorrendo com passos lentos a biblioteca, mas um leitor em prontidão, conectando-se entre nós e nexos num roteiro multilinear e labiríntico que ele próprio ajudou a construir ao interagir com os nós entre palavras, imagens, documentação, músicas, vídeos etc.
Contudo, ainda em meio ao século XXI e a seu desenfreado desenvolvimento, alinhado para que as pessoas tenham suas rotinas facilitadas, os smartphones ganham ainda mais destaque, tornando-se quase como extensões dos corpos humanos. Nesse contexto, surge também um novo leitor. Segundo os estudos de Santaella (2013), o leitor ubíquo descende dos leitores referenciados anteriormente e apresenta características muito semelhantes a eles, visto que não há um processo de agregação e de desenvolvimento, ou seja, cada um "aciona habilidades cognitivas específicas de modo que um não pode substituir o outro. Cada um deles contribui de modo diferencial para a formação de um leitor provido de habilidades cognitivas cada vez mais híbridas e cada vez mais complexas" (SANTAELLA, 2013, p. 281). Por conseguinte, o leitor ubíquo segue lendo e "transitando entre formas, volumes, massas, interações de forças, movimentos, direções, traços, cores, luzes que se acendem e se apagam, pistas, mapas" (SANTAELLA, 2013, p. 278). Em suma, sua prática leitora se assemelha com a do leitor 


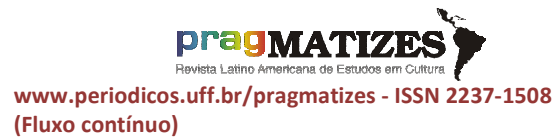

movente; como também com a do leitor imersivo, que por meio do uso do celular

[...] pode penetrar no ciberespaço informacional, assim como pode conversar silenciosamente com alguém ou com um grupo de pessoas a vinte centímetros ou a continentes de distância. (SANTAELLA, 2013, p. 278)

O leitor ubíquo, porém, possui uma capacidade distinta dos demais leitores: a de estar presente nos mais diversos lugares e em qualquer tempo. Isso só é possível porque, em conformidade com Santaella (2013, p. 278), a ubiquidade refere-se justamente "a sistemas computacionais de pequeno porte, e até mesmo invisíveis, que se fazem presentes nos ambientes e que podem ser transportados de um lugar a outro". Nessa acepção, o aparelho celular, como um dispositivo que permite não apenas a conversação, mas também estabelece várias outras relações multimídiais, passa a ser imprescindível para o leitor ubíquo, bem como passa a ser uma marca de sua identidade.

Passados alguns anos desde a publicação de Santaella (2013) a respeito do leitor ubíquo, percebemos, além desses aspectos referenciados por ela, que com esse sistema de comunicação multimodal, multimídia e portátil em mãos, os sujeitos do século XXI passaram a se comunicar de forma ainda mais rápida, a registrar suas rotinas de forma instantânea por redes sociais e a seguir e recriar os "ensinamentos" dos fenômenos Youtubers e Instagramers, os quais descobriram rentáveis formas de viver, haja vista que estão plenamente inseridos em uma recepção que não apenas os recebe, segue e curte, mas que se potencializa e amplia pela energia de seus conteúdos e pela acessibilidade de suas formas de comunicação. Ademais, os novos leitores - essa nova recepção, que aqui consideramos leitores ópticos passaram a adorar e a consumir, quase que compulsivamente, as criações verbais e imagéticas de seus ídolos porque simplesmente se sentem atraídos por eles. Esse é o caso de Frida Kahlo, "redescoberta" e "consumida" atualmente. Esse entendimento será apresentado na última seção, quando mostramos os atratores visuais de Frida Kahlo no século XXI e quem são, 


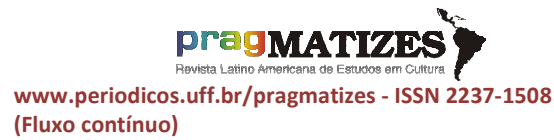

(Fluxo contínuo) possivelmente, os leitores erópticos ${ }^{3}$ atraídos por ela. Para melhor compreensão desta ideia, antes, verificamos o ponto de vista de Massimo Canevacci (2008) sobre os atratores visuais.

\section{Fetichismo e atração visual}

De forma constante, observamos mudanças representativas na sociedade quanto a novas nuances de valores e padrões estéticos. A estética é um movimento que rediscute padrões e, muitas vezes, elege o que porventura poderia ser refratado ou repelido como uma nova forma de beleza. Isso ocorre porque se encontra em jogo um processo que significa mais do que ser bonito ou desejável. Em outras palavras, o sentido das coisas busca a sedução e isso pode estar fora das linhas da simetria e da proporcionalidade. Nesse aspecto, a sedução parece uma espécie de salvaguarda ao que poderia se adequar à pureza das políticas dominantes, que oprimem a originalidade, aquilo que se tem como identidade. Na linha do que seduz e

\footnotetext{
${ }^{3}$ Eróptico é o termo utilizado por Canevacci (2008), em nosso trabalho optamos pelo emprego, de forma analógica, do termo óptico.
}

perigosamente atrai, fora das contingências de um belo pacificado, passivo de visão, iluminado e puro, o fetichismo visual pode evitar a objetivação dos sujeitos, já que a sedução confere subjetividade ao que se mostra, olhar ao que se deixa ver, corpo ao que se poderia reificar, erotismo que jamais se deixa possuir totalmente.

Aliás, "1.Trazer, puxar ou solicitar para si. 2. Seduzir, fascinar. 3. Chamar, incitar a aproximar-se. 4. Provocar, suscitar (opiniões, sentimentos, etc.)" é a definição encontrada no dicionário Aurélio sobre o verbo "atrair" (FERREIRA, 2010, p. 77) e que nos auxilia a entender o conceito que Massimo Canevacci trata no livro intitulado Fetichismos visuais: corpus erópticos e metrópole comunicacional (2008). O ato de atrair configura uma ação dupla: ao mesmo tempo em que o objeto atrator puxa para si o que deseja, o objeto (ou o sujeito) atraído é seduzido, ou seja, sua atenção volta-se para aquela força atratora. Canevacci (2008), assim, principalmente sob a perspectiva do universo configurado pela cultura digital e ampliado nas áreas metropolitanas, expõe sobre o que 


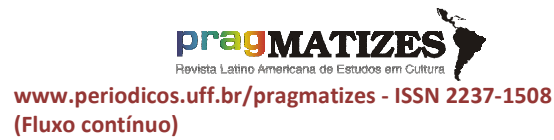

(Fluxo contínuo) pode potencializar os efeitos de algo a atração - que já instaura e se segmenta há muito tempo e em distintas áreas, como na arte, na moda, no cinema, entre outras, de modo a comprovar uma "[...] mutação visual dos fetichismos incorporados por movimentos atratores. Atratores irregulares e perversos" (CANEVACCI, 2008, p. 15).

De acordo com Canevacci (2008, p. 16), os atratores configuramse como "códigos mínimos em detalhes mais ou menos micrológicos que têm a capacidade de exercitar uma potente atração visiva, graças ao elevado conteúdo de fetichismo visual incorporado". Mostram-se como aqueles elementos que, temporariamente, têm 0 poder de "congelar" o tempo e de suspender a razão, atraindo os olhares, as atenções e os julgamentos. Ainda, o atrator "anula temporariamente 0 movimento do olho exercendo um poder que une o olhar e a coisa e que determina os novos cursos dos fetichismos visuais difundidos na metrópole comunicacional" (CANEVACCI, 2008, p. 16). Logo, os elementos atratores, de naturezas diversas, demonstram que por si bastam, já que eles próprios se fazem comunicação.

Nesse sentido, os fluxos comunicacionais criados a partir de movimentos ou de objetos atratores, caracterizam-se

[...] por uma taxa crescente de fetichismo visual de matriz digital. (Os fluxos comunicacionais) disseminam e incorporam minuciosos atratores: fragmentos simbólicos que atravessam os modos perceptíveis de um olhar que de modo nenhum é ingênuo ou manipulável, embora condicionado à decodificação. Desejoso de selecionar e distinguir. De ser selecionado e de ser distinguido (CANEVACCI, 2008, p. 14-15, grifo do autor).

Segundo o autor, o que lhe chamou a atenção para a realização do estudo sobre os atratores visuais, quase uma exigência pessoal obsessiva, foi o fato de que há uma "mutação visual dos fetichismos incorporados por movimentos atratores" (CANEVACCI, 2008, p. 15, grifo do autor). Ou seja, com o passar do tempo e com a mudança dos comportamentos políticos, há uma transformação dos "corpos ambíguos fetichisticamente envolvidos e de qualquer maneira induzidos por um olhar etnográfico perigosamente fetichista" (CANEVACCI, 2008, p.15). 
Esse aspecto interessa-nos de maneira especial, pois o fenômeno Frida Kahlo irrompe como um movimento fetichista muito recente, resultado sobretudo dos fluxos comunicacionais em que os leitores ubíquos - que se transformaram em leitores ópticos - participam de forma ativa ao consumir o resultado da reificação de Frida Kahlo, isto é, da objetificação de sua criação artística, uma perversão fetichista conflagrada digitalmente. Esse aspecto confirma aquilo que Canevacci (2008) discorre a respeito da transposição limítrofe da pele em relação ao corpo:

[...] quando a pele transpõe seus limites, ela se liga aos tecidos "orgânicos"da metrópole. Nesse sentido, o corpo não é apenas corporal. O corpo expandido em edifícios, coisas-objetosmercadorias, imagens, é aquilo que se entende aqui por fetichismo visual (CANEVACCI, 2008, p. 18).

Durante a realização de seu estudo, Canevacci (2008) fez uma seleção de imagens, pertencentes à cultura visual,com potencial fetichista. Ele percebeu, com isso, uma disjunção que turbava "os velhos dualismos - o orgânico e o inorgânico, as coisas e o humano, o material e o imaterial, a natureza e a cultura, o masculino e o feminino, os corpos e a urbanística para sintetizá-los na direção de alguma coisa perversa e normal" (CANEVACCI, 2008, p. 20). Logo, a lógica consumista e transgressora do olhar passou a ser normalizada no cotidiano social.

Por meio de sua análise, Canevacci (2008) definiu três conceitos que para nosso estudo também se fazem imprescindíveis quanto à movimentação fetichista sócio-histórica: bodyscape, location e dress-code. O primeiro refere-se a um "corpo panorâmico que flutua entre os interstícios da metrópole comunicacional. Atrai e é atraído pelas locations mutantes. É uma location do corpo. Corpo espaçado" (CANEVACCI, 2008, p. 42). Podemos inferir, a partir desta definição, em analogia às apresentações de Canevacci (2008), que o bodyscape se constrói assentado na fuga dos padrões impostos de uma determinada situação, de um tempo ou de um espaço; constrói-se a partir de uma location, ao passo que também se põe em seus interstícios, onde paira, favorece sua mutação ou, ainda, em contraste, conflitua com esta circunstância. Ademais, o bodyscape 


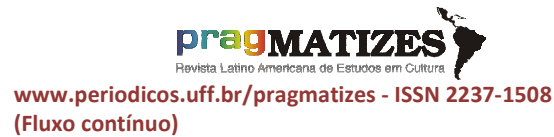

[...] persegue acelerações dos códigos antes invisíveis que um corpo insere para assemblages sucessivas ao longo da própria configuração para construir uma fisionomia temporária. Publicidade, arquitetura, arte, em particular, body-art e arte digital, coreografia, design e webdesign, tatuagens-escarificações-

piercing, todos são configurações parciais uma vez bem separadas e que agora citam, vestem, influenciam umas às outras ao longo dos itinerários flutuantes e fortemente sincréticos (CANEVACCI, 2008, p. 30).

Assim, um portador de bodyscape mostra-se alguém que aplica uma semiótica espontânea ao próprio corpo, um intérprete ativo como também seu leitor eróptico apresenta-se. De forma consequente, ele narra "[...] as próprias mudanças comunicacionais e os próprios desejos sensoriais: isto é, é a comunicação, entrelaçada ao consumo e à cultura, que aqui redefine as fisionomias recortadas ao invés da sociedade" (CANEVACCI, 2008, p. 32).

Por sua vez, o segundo conceito, location, mostra-se como "um lugar, um espaço ou uma zona intersticial que inscreve movimentos simétricos fora dos corpos panorâmicos" (CANEVACCI, 2008, p. 42). Na perspectiva de Canevacci
(2008, p. 32), a location manifesta "[...] uma identidade dada como fixa, única, compacta, certa, tradicional",e igualmente aparece como um espaço que, talvez, se mostre de complexa articulação com o conceito de identidade.Porém, as duas definições -identidade e espaço - demonstram intersecção na medida em que compactuam na movimentação do ambiente eletrônico (e-space), “[...] onde se estende a web que tece fios flutuantes multividuais, interconectados e mix-midiais" (CANEVACCI, 2008, p. 33, grifos do autor)

Ambos os conceitos, bodyscape e location, em conformidade com Canevacci (2008), abrem-se para o terceiro conceito, dress-code, o qual também explicitamos aqui. Antes, contudo, é válido enfatizar que os dois primeiros

[...] exprimem atratores sexuados em um jogo performativo com contínuas citações, trocas, inversões, perversões, multiversões, subversões. Ambos são como duas identidades fluidíssimas e mutantes, que não têm gênero (masculino-feminino), lugar (público-privado), ontologias (orgânico-inorgânico), morais (bem-mal), dicotômicas (natureza-cultura), hierárquicas (alto-baixo): ao contrário, percorrem os territórios do além 
de. A força de tais atratores não se opõe (ao poder, por exemplo), mas o ultra-passa. Ultra-passante (CANEVACCI, 2008, p. 37, grifos do autor).

Logo, a última definição, dresscode, indica "[...] uma pragmática do corpo que se modifica, constrói espaços, ressignifica fetiches através de escolhas cosméticas de um sujeito mutante. [...] é a chave de acesso que favorece 0 trânsito semiótico entre location e bodyscape" (CANEVACCI, 2008, p. 42). Esse conceito, entre os já apresentados, identifica-se mais proximamente com a personagem objeto de análise deste artigo, Frida Kahlo, já que

[...] o dress envolve e move
aquelas práticas que aqui
caracterizam escolha,
incorporação, combinação,
composição/assemblage, cut-up,
morphing, e, enfim, a seleção
decisiva em direção ao contexto
onde expor o resultado final.
Code é um código que indica as
escolhas da transformação, as
lógicas sob e sobre a atividade
semiótica que o corpo adquire
sobre a base de escolhas
espontâneas/construídas por
parte do sujeito (CANEVACCl,
2008, p. 38, grifos do autor).

Essa acepção faz-se essencial porque está intimamente relacionada às anteriores: sintonizados, o bodyscape e a location convergem e são naturalmente atraídos pelo dresscode. Com isso, o dresscodeapresenta-se como uma voz polifônica e dissonante que ecoa em cima dos códigos expostos, social e historicamente. Nas palavras de Canevacci (2008, p. 39, grifos do autor),

são as notas de um verdadeiro sound-design que - como a trilha sonora de um filme, do próprio filme corpo-no-espaço transformam o corpo em paisagem acústica, que performa um mix de linguagens, cujas distinções entre linguagem do corpo, da cosmética, do estilo, das roupas centrais e dos acessórios periféricos se tornam inúteis. Os atratores emergem em uma espécie de alfabeto imagético e sonoro - um enigma a ser decifrado - no desempenho de um papel integrante mais que suplementar do eu-narrador.

Sendo assim, situado entre o bodyscape e a location, isto é, no interstício dos dois, o dress-code mostra-se como a chave de acesso a eles. Para conhecer os anteriores, analise-se, assim, toda a linguagem expressa pelos atratores semióticos que esse código escancara aos leitores erópticos numa narrativa singular altamente fetichista. É o que se pretende realizar na análise que passamos a discorrer nas próximas 


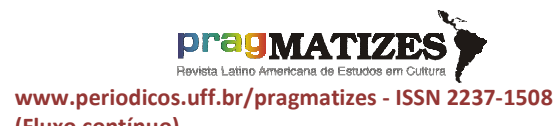
(Fluxo contínuo) seções. Um convite para conhecer o dress-code de Frida Kahlo, ela que, como bodyscape, marcou seu território, sua location, e ganhou o mundo. Antes, entretanto, delineamos os procedimentos metodológicos que sustentam a pesquisa.

\section{Procedimentos metodológicos}

O estudo que apresentamos neste artigo, de acordo com as definições de Prodanov e Freitas (2013), quanto à natureza, estrutura-se como qualitativo, e quanto aos objetivos, como descritivo. Em relação ao procedimento técnico, caracterizase como uma pesquisa bibliográfica, alicerçada sobretudo nas considerações de Lucia Santaella (2004, 2013) a respeito dos diferentes tipos de leitores, e nos estudos de Massimo Canevacci (2008) sobre os atratores visuais.

Já o processo de coleta de dados ocorreu por meio da observação de elementos recorrentes na bibliografia sobre Frida Kahlo, principalmente quanto aos aspectos visuais e sua relação intrínseca com o contexto sócio-histórico mexicano. Através dessa observação analítica, tem-se as seguintes categorias de análise: 0 contexto no qual Frida baseou seus posicionamentos políticos, a Revolução Mexicana e seus desdobramentos;a época em que ela esteve viva, em meio às tragédias pessoais e à criação de sua arte;e o momento de sua ascensão como figura pop, já no século XXI.

Considerando essas informações, dividimos o texto em duas partes. A primeira atende à fundamentação teórica, na qual apresentamos $\quad 0 \quad$ conteúdo indispensável à análise com base em Canevacci (2008) e em Santaella (2004, 2013). Por sua vez, na segunda parte, preocupamo-nos em apresentar o já citado enquadramento da vida de Frida Kahlo, sobretudo quanto a suas origens e a seus posicionamentos ante diferentes aspectos, como o amor, a história e a sociedade. Para tanto, baseamo-nos nas produções de Fernández (2002), Florencio (2014), Henestrosa (2012), Herrera (2011), Kettenmann (2015) e Zamora (2007). E, por fim, na última seção, tecemos a análise quanto aos atratores visuais e aos leitores erópticos, por uma perspectiva fetichista a respeito de Frida Kahlo. 
Frida, sua história e a de seu país

Magdalena Carmen Frida Kahlo

y Calderón nasceu em Coyoacán, na

Cidade do México, na mesma residência - conhecida como Casa Azul - em que faleceu, no ano de 1954, e que hoje abriga o Museu Frida Kahlo. Trata-se de um dos espaços culturais mais conhecidos e visitados do México e, talvez, do mundo, já que, todos os anos, recebe milhares de turistas de diferentes países, sem contabilizar aqueles leitores que realizam a visita virtual ao museu, outra possibilidade existente para que se conheça o lugar em que Frida Kahlo viveu, espaço no qual constituiu seu refúgio e que ainda representa a extensão de seu próprio corpo. Além disso, diz respeito a um dos lugares que testemunhou as fraturas físicas e emocionais da artista, como em sua infância, quando as redondezas da casa - e ela própria - foram palco da Revolução Mexicana.

A história de Frida começa - e se mescla - à Revolução Mexicana e ao México. Nas paredes da casa de Coyoacán, em um dos quartos, acima de um armário, lê-se a seguinte frase: “aqui nació Frida Kahlo El día 7 de julio de 1910". De acordo com Herrera
(2011, p. 17-18), as palavras foram escritas quatro anos após sua morte, quando a casa se tornou um museu. Porém, o autor esclarece que, conforme a certidão de nascimento da artista, ela nasceu em 6 de julho de 1907. Portanto,

talvez optando por uma verdade mais estrita do que $o$ fato permitiria, ela escolheu nascer em 1910, ano da eclosão da Revolução Mexicana. Uma vez que era filha da década revolucionária, quando as ruas da Cidade do México estavam coalhadas de caos e derramamento de sangue, Frida decidiu que ela e o México moderno haviam nascido no mesmo ano (HERRERA, 2011, p. 18).

Independentemente de sua data de nascimento, Frida viveu aquele momento histórico decisivo e, nas páginas de seu diário, registrou as primeiras memórias sobre o período:

Recuerdo que yo tenía 4 años cuando la decena trágica. Yo presencié con mis ojos la lucha campesina de Zapata contra los carrancistas. Mi situación fue muy clara. Mi madre por la calle de Allende - abriendo los balcones les daba acceso a los zapatistas haciendo que los heridos $y$ hambrientos saltaran por valcones [sic] de mi casa hacia la "sala". Ella los curaba y les daba gorditas de maíz único alimento que en ese entonces se podía conseguir en Coyoacán. Eramos [sic] cuatro hermanas Matita Adri 


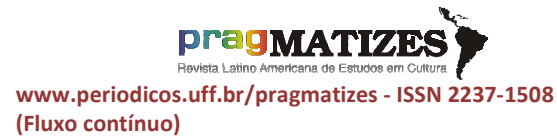

yo (Frida) y Cristi, la chaparrita. [...] La emoción clara y precisa que yo guardo de la "revolución mexicana" fue la base para que a los 13 años de edad ingresara en la juventud comunista (KAHLO, 2014, p. 282).

Esse importante e decisivo momento histórico para o México também se mostrou crucial para a vida de Frida Kahlo. Direta ou indiretamente, a defesa das classes menos valorizadas, aquilo que representou a Revolução Mexicana, refletiu em sua formação pessoal - em seu caráter, em suas atitudes e em seu fazer artístico. Ao longo de sua vida, a pintora fez questão de mostrar suas raízes indígenas, ora exaltando seus traços físicos, ora ornamentandose com roupas e acessórios, ora demonstrando sua repulsa àqueles que não desejavam a igualdade, como escreveu em seu diário:

[...] He leído la historia de mi país y de casi todos los pueblos. Conozco ya sus conflictos de clase y económicos. Comprendo claramente la dialéctica materialista. [...] Por primera vez, en mi vida la pintura mía trata de ayudar a la línea trazada por el partido. Realismo Revolucionario. Antes solamente fuí mi mas [sic] antigua experiencia. Soy solamente una célula del complejo mecanismo revolucionario de los pueblos por la paz y de los pueblos nuevos, soviéticos - chinos checoeslovacos, polacos ligados en la sangre a mi propia persona. $\mathrm{Y}$ al indígena de México. Entre esas grandes multitudes de gente asiáticas, siempre habrá rostros míos - mexicanos - de piel oscura y bella forma de elegancia sin límite, también estarían ya liberados los negros, tan hermosos y tan valientes. (Mexicanos y negros están por el momento sojuzgados por países capitalistas sobre todo Norte América - (E.U. e Inglaterra) (KAHLO, 2014, p. 255-257).

Isso exposto, para melhor compreensão sobre esse período, traçamos uma concisa retomada histórica sobre o estopim da Revolução Mexicana e o que ela representou. Nosso objetivo não é detalhar o que aconteceu na época, até porque a história do México, assim como ele próprio, mostra-se rica e abundante em personagens reais que transformaram o país e as gerações futuras. Buscamos, aqui, reconstituir uma parte da história de Frida Kahlo ao mostrar suas motivações políticas, sociais, artísticas e pessoais, suas escolhas e o seu lugar. 
A inspiração de Frida: panorama histórico do México entre os séculos XIX e XX

No final do século XIX, o México era comandado por líderes que inibiam a reforma agrária e as melhores condições para aqueles que viviam em precariedade no campo, uma histórica desvalorização das classes menos abastadas. No início da Revolução Mexicana, Porfírio Díaz era o presidente, no período que ficou conhecido como Porfiriato (1876 a 1911), quando a democracia verdadeira estava distante da realidade, já que em seu mandato tentou controlar todas as classes com o apoio do Exército, em uma contínua centralização do poder, mesmo que para isso despojasse campesinos e indígenas de suas terras e reprimisse os opositores políticos.

Nesse sentido, o presidente realizou a expropriação de territórios indígenas que não haviam sido demarcados e obrigou as pessoas desenraizadas de suas origens e de sua cultura - a trabalhar de forma precária em outros lugares, principalmente na Cidade do México, capital do país, aumentando a população urbana periférica e desfavorecida economicamente, ao mesmo passo em que favorecia os latifundiários, os quais ocuparam as antigas terras indígenas.

À época, era a elite quem escolhia o líder que Ihe interessava a fim de garantir a manutenção de seus privilégios. Esses benefícios para as classes mais altas, não por acaso, alinhavam-se diretamente aos interesses do país vizinho, os Estados Unidos. Outrossim, as relações entre Estados Unidos e México, no século XIX,começaram a se estreitar, posto que Porfírio Díaz concedeu benefícios de terras, campos petrolíferos e mineradoras para empresas americanas e britânicas, adaptando-se ao capital estrangeiro e desenvolvendo seu país, mesmo que isso o comprometesse democrática e culturalmente.De forma consequente, o processo de industrialização é iniciado. Em contrapartida, se forma um proletariado que se associaria, mais tarde, aos camponeses para uma mudança de realidade.

Começa, então, ao final do Porfiriato, no início do século $\mathrm{XX}$, a luta de classes. Segundo Fernández (2002), os movimentos de resistência ganharam força em busca de uma 
reforma agrária, tendo como líderes Pancho Villa e Emiliano Zapata. O político Francisco Madero, rival de Porfírio Díaz, une-se ao grupo campesino para fortalecê-lo. É Madero quem começa uma revolução, agora por outra frente - na cidade -, defendendo o voto secreto para a escolha do governo e a criação de uma legislação trabalhista.

Essa pressão popular corrobora para a criação da Revolução Mexicana, o que obriga Porfírio Díaz a renunciar de seu cargo na presidência. Logo, trava-se um pacto entre os três líderes e a nova presidência passa para as mãos do líder urbano Madero. O problema, porém, é que as mudanças sociais não acontecem, já que Madero deixa a situação como estava: passa a evitar a reforma agrária - principal proposta do grupo e mantém as relações com os Estados Unidos, até porque não interessava ao país norte-americano que os líderes camponeses assumissem.

Devido ao extremo conservadorismo do governo e ao não atendimento às classes campesinas e aos operários, Zapata rompe com o presidente e afirma que a revolução ainda não tinha acontecido, mas que deveria ocorrer com a reforma agrária imediata (FLORENCIO, 2014). Entretanto, o movimento começa a angariar o ódio, inclusive de outros países, além dos Estados Unidos, até porque o mundo estava em guerra naquele momento, e as organizações sociais assustavam a todos porque representavam a ascensão do socialismo. Em suma, era preciso tirar Zapata de cena.

$\mathrm{Na}$ perspectiva de Florencio (2014), em 1911, Madero estava prevendo que aconteceria uma revolução, uma suposta guinada à esquerda de liderança, e ele já não conseguia controlar seus antigos parceiros. Por isso, os Estados Unidos intervêm: se aliam ao general Victoriano Huerta e retiram Madero do poder, episódio que ficou conhecido como Contrarrevolução. Assim, de forma irônica, em consonância com Fernández (2002), o líder popular que assumiu por meio de um golpe também é destituído por um.

Contudo, apesar de todos os esforços norte-americanos e de seus aliados mexicanos, especialmente Huerta, os líderes populares mexicanos não cedem e tampouco são vencidos. Dentro dos referidos grupos 


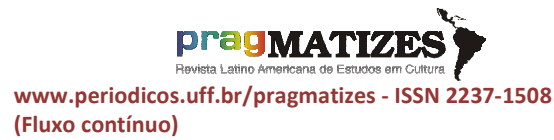
(Fluxo contínuo) revolucionários, alguns líderes se destacaram por sua moderação, como Venustiano Carranza, que era secretário de Guerra e da Marinha de Madero, e tinha em seu projeto de governo algumas ideias populares, mas não possuí ao pensamento de esquerda - estatização e coletivização das propriedades mexicanas. De acordo com Florencio (2014), Carranza, ao assumir o governo no lugar de Huerta, garante apoio internacional e conta com os líderes populares, principalmente Zapata e Villa, consolidando uma suposta Revolução Mexicana.

Vale dizer que Carranza constitui um novo estilo de governo, de caráter central,o que acalma, em partes, a população; dado que evita uma estatização completa e uma tomada dos Estados Unidos. Apesar disso, nas palavras de Florencio (2014, p. 112), "as medidas anunciadas pelo novo governo não atenderam aos anseios da população e seguiu-se uma onda de greves de grandes proporções, afetando setores nevrálgicos, tais como o petrolífero, o minerador, o têxtil, o de construção civil e o agropecuário". O erro de Carranza, ainda segundo Florencio
(2014), foi pensar que já havia atingido os objetivos da Revolução, quando na verdade reprimiu 0 movimento trabalhista e rompeu os laços entre operários urbanos e camponeses depostos de suas terras. Consequentemente, o presidente perde a governabilidade. E, "mais uma vez, o aliado de ontem, o general Obregón, virou o inimigo de hoje: Carranza foi assassinado em uma emboscada preparada por Obregón, que assumiu a presidência em 1920, ficando no poder até 1924" (FLORENCIO, 2014, p. 113).Com Obregón no poder, acontece a redistribuição de terras aos camponeses e o investimento em escolas rurais - o novo líder percebe que a base de poder mexicano residia no campo e não na estrutura fundiária que Carranza voltava a defender, preceito herdado de Porfírio Díaz.

Para mais, convém destacar que um dos grandes legados da Revolução Mexicana é a Constituição de 1917 (em vigor), mas nunca aprovada em sua totalidade por Carranza. No documento, entre outras conquistas, estão a "[...] proibição de a Igreja e estrangeiros terem a propriedade do subsolo mexicano; fim 


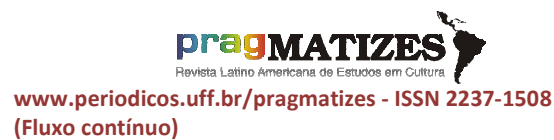

do monopólio da Igreja no campo da educação; e instituição do salário mínimo, de direitos trabalhistas avançados e de um sistema de previdência social" (FLORENCIO, 2014, p. 113). Trata-se de um grande avanço no percurso democrático mexicano, decisivo para a constituição de outras aquisições nos anos seguintes.

E foi essa a Revolução que inspirou a arte no México, sobretudo a pintura, colocando o país na vanguarda artística, por meio de grandiosas obras, principalmente os murais concebidos por artistas como Diego Rivera, grande amor de Frida Kahlo. Através destas criações visuais - as obras de Frida e os murais de Diego Rivera, entre outros importantes pintores mexicanos, como Orozco e Siqueiros, também muralistas - é possível recordar e reviver a memória popular das grandes revoluções, uma tentativa de reconstrução da identidade mexicana que se consolidou por meio da memória artística.

Frida e suas fraturas: a dor e a identidade
A pintora mexicana Frida Kahlo teve uma vida marcada pela dor. Quando criança, sofreu com as consequências físicas da poliomielite; mais tarde, quando jovem, em setembro de 1925, ao sofrer um acidente em um bonde, o qual se chocou contra um ônibus, teve seu corpo praticamente dilacerado e reconstruído após inúmeras cirurgias. Seus movimentos passaram a ser ainda mais restritos e representativa parte de sua vida resumiu-se ao contíguo espaço de seu quarto, às estadias nos hospitais, para complicados procedimentos cirúrgicos, e às visitas aos médicos. Contudo, ao mesmo tempo em que seu corpo se dilacerou fisicamente, a arte passou, literalmente, a iluminá-la.

Segundo Fuentes (2014, p.12), quando sofreu o acidente, estava no veículo, provavelmente, um pintor de casas que carregava um pacote com ouro em pó e, com a força da colisão, Frida ficou nua e coberta com o ouro como uma previsão do brilho que mostraria em sua vida (e mesmo após sua morte):

[...] el impacto del choque dejó a Frida sangrienta y desnuda, pero cubierta de oro. Despojada de la ropa, el cuerpo desnudo de Frida 


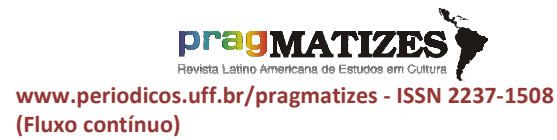

recibió, como un rocío fantástico, la llovizna de un paquete de oro en polvo que llevaba a su traje un artesano".

Frida, depois deste momento, passou a pintar a revolta, o escárnio, a dor e o amor; pintou a si mesma e ao México que tanto amava; transformou-se ela própria em um corpo artístico e atrator.

Em suma, após o acidente, a pintura passou a ser a principal válvula de escape de Frida, uma vez que a artista começou a pintar logo que recobrou alguns movimentos. Impossibilitada de levantar-se e com um desejo quase inexplicável de expressar-se, ela começou sua entrega à arte. Certa vez, Frida revelou essa ânsia ao escrever uma carta destinada a seu amigo Antonio Rodríguez:

Mi mamá mandó hacer con un carpintero un caballete, sí así se le puede llamar a un aparato especial que podía acoplarse a la cama donde yo estaba porque el corset de yeso no me deja sentar. Así comencé a pintar el cuadro, un retrato de una amiga mía. Después hice dos retratos más de mis amigos de la escuela, luego un autorretrato $y$, cuando ya pude sentarme, pinté dos o tres cosas más...Desde entonces, mi obsesión fue recomenzar de nuevo pintando las cosas tal y como las veía como yo las veía con mis propios ojos y nada más... (ZAMORA, 2007, p. 251).

Os primeiros rabiscos dessa história começaram, como a própria Frida manifestou, pelos retratos de amigos e de pessoas conhecidas. Em seguida, desenhou paisagens urbanas, alguns esboços de figuras humanas usando lápis e papel; mas foi um ano mais tarde que ela pintou seu primeiro autorretrato ("Autorretrato con traje de terciopelo"), séria, contemplativa, aos 19 anos. Uma pintura em tons mais escuros, com poucos detalhes, ao estilo europeu inclusive em relação à vestimenta, um requintado vestido de modelo renascentista, e ao penteado do cabelo, um elegante coque -, ou seja, ela ainda não expressava de forma artística a marcante presença de sua herança indígena. Como fundo da tela, Frida pintou o mar com tom azul escuro, profundo e soturno, como "símbolo de sua vida", conforme contou por meio de uma carta destinada a Alejandro Arias, seu namorado da época e para quem fez a aquarela (ZAMORA, 2007). A partir do segundo autorretrato, no entanto, seu estilo passa a ser outro, como uma 


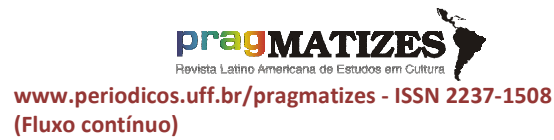

(Fluxo contínuo) mulher do povo, uma mexicana. De acordo com Herrera (2011, p.140, grifos do autor),

sua blusa rendada é um exemplar
típico das roupas baratas
vendidas no México em bancas
do mercado, e suas joias -
brincos de estilo colonial e contas
de jade pré-colombianas -
simbolizam a identificação da
pintora como mestiza (pessoa
que provém do cruzamento de
sangue indígena e espanhol. "Em
outra época eu me vestia como
menino, com cabelo raspado,
calças, botas e jaqueta de couro",
Frida disse certa vez. "Mas
quando eu ia ver Diego punha um
traje tehuano".

A arte, todavia, segundo Zamora (2007), já havia entrado na vida de Frida um pouco antes do acidente, ainda que indiretamente. Ela, em idade escolar, viu o famoso muralista Diego Rivera pintar, em 1921, no colégio onde estudava, o mural "La creación", o qual muito tempo depois foi destruído por um movimento estudantil. Nessa época, já irreverente, Frida contemplava o trabalho de Diego, fazia todo o tipo de brincadeiras com ele e, inclusive, provocava o ciúme da então esposa do pintor, Lupe Marín. Um tempo mais tarde, após sua parcial recuperação do acidente, e tomada pelo anseio da aprovação de sua arte, a pintora levou quatro telas para que Diego as avaliasse, enquanto ele pintava mais um de seus murais na Secretaria de Educação da Cidade do México.

O artista, muito simpático, disse-Ihe que seu autorretrato parecia ser muito original, mas que os outros, de natureza diferente, pareciam ser resultado de influências externas, de outros artistas. Sugeriu-Ihe, então, que pintasse outro quadro e que voltasse no próximo domingo para lhe mostrar; foi o que Frida fez, e o famoso pintor, reconhecido mundialmente, anuiu o talento da jovem. Ela, de acordo com Zamora (2007), voltou outras inúmeras vezes para visitar Diego, quando o romance entre os dois começou; e não muito mais tardiamente, em 1929, os dois artistas se casaram, sob desaprovação da família de Frida: "decían que era como casar a um elefante com una paloma" (ZAMORA, 2007, p. 40).

$$
\text { Pouco tempo após } 0
$$

casamento, o casal mudou-se para o estado mexicano de Morelos, instalando-se naconhecida cidade de Cuernavaca, onde Diego pintou um mural no Palácio de Cortés, patrocinado pelo embaixador americano Dwight W. Morrow, trabalho 
que the rendeu um valor muito alto para a época (ZAMORA, 2007). Mais tarde, em meio a conflitos políticos e a desvalorização da arte muralista no México, Frida e Diego viajaram para os Estados Unidos para que ele pintasse murais pelos quais fora contratado, e onde também deu aula de afrescos (HERRERA, 2011).Assim, passaram pelas cidades de São Francisco, Detroit e Nova York. Conforme Zamora (2007), foi uma época muito diferente na vida do casal, principalmente para Frida, que teve de se reinventar para que não the restasse o papel de coadjuvante como esposa do grande protagonista da arte muralista, Diego Rivera, perdendo o brilho a que estava destinada. A biógrafa da pintora descreve aqueles momentos:

[...] (Frida) se codeaba con embajadores, grandes empresarios como los Ford y los Rockefeller, perfeccionaba su inglés, que llegó a dominar incluso en expresiones idiomáticas y juegos de palabras; pulía más y más su imagen y su incisivo humor. Creaba con cuidado el espectáculo de su presencia para atraer la atención y así no quedar constreñida al papel de la esposa del maestro y pintaba algunos cuadros, principalmente retratos de las personas que los rodeaban en esas ciudades (ZAMORA, 2007, p. 43).
Por onde passava, Frida marcava com sua presença exótica e, particularmente, gostava do efeito disso. Segundo Herrera (2011), ao contrário do que se poderia imaginar, Diego não sentia ciúmes, mas se orgulhava de Frida e da atenção que ela recebia, o que aparecia de forma constante em seus relatos, como quando contou sobre uma festa para a qual foram convidados por Henry Ford, empreendedor e engenheiro mecânico, dono da Ford Motor Company: "Linda em seu traje mexicano, Frida tornou-se o centro das atrações. Ford dançou com ela várias vezes" (HERRERA, 2011, p. 172).

Todavia, a despeito dessa aparente tranquilidade, de luxo e de glamour, Zamora (2007) salienta que foi um tempo difícil em outros aspectos. O trabalho de Diego, apesar da valorização da arte muralista e de seu sucesso, sofreu duras críticas, tanto pelos resultados quanto pelo seu teor político. Chegou a ter destruído o seu mural no Rockefeller Center de Nova York, acusado por algo que, todos sabiam, já fazia parte de seu repertório e constituía sua própria essência como alguém que conhecia a si próprio e que se posicionava como 
tal, ou seja, o seu perfil socialista, altamente de esquerda. Por seu lado, após quatro anos vivendo nos Estados Unidos, Frida sentia saudades do México e das pessoas de lá, embora empreendesse curtas visitas a seu querido país. Nesse período, ela perdeu sua mãe e sofreu sérios problemas ginecológicos, resultados de um aborto, algo que deixou expresso em um quadro que recebeu o nome do hospital para o qual foi levada e no qual permaneceu aproximadamente 15 dias - "Hospital Henry Ford".

Também nessa época, em1933, já muito cansada do tecnicismo e da falta de humanidade americana, ela pintou um quadro que fugia dos estândares de sua pintura: "Mi Vestido Cuelga Ahí", no qual, ironicamente, mostra um vestido sozinho, sem nenhuma figura humana, como era natural nas pinturas de Frida. Mas, independentemente dessa peculiaridade, a obra é considerada um autorretrato devido à presença de sua marca (elemento atrator): a roupa tipicamente tehuana.

Nessa tela, feita à tinta óleo e colagem, a única com esta técnica, Frida imprime uma profusão de imagens, construídas detalhe a detalhe, em uma entrega artística que já começava a lhe ser característica. De acordo com Kettenmann (2015, p. 36), o quadro "está repleto de símbolos da sociedade industrial da América moderna e aponta para a decadência social e para a destruição de valores humanos fundamentais". A artista mexicana começou sua obra quando já estava farta dos Estados Unidos, enquanto ela e Diego Rivera moravam em Nova York e já haviam passado todo tipo de situação: de recepções nas casas de grandes influências americanas, festas e luxuosos jantares, a escândalos políticos e humilhações públicas devido aos posicionamentos políticos socialistas de Diego, que renderam muitas manchetes jornalísticas, conforme elucida Herrera (2011).

Atrás do referido quadro, a artista escreveu com giz a seguinte frase: "Pintei este quadro em Nova York, quando Diego estava pintando o mural no Rockefeller Center" (HERRERA, 2011, p. 215). Algum tempo depois, Frida Kahlo presenteou a pintura a seu grande amigo, o médico torácico Leo Eloesser, o qual conheceu enquanto esteve internada 
em São Francisco, em quem confiava e sempre escrevia cartas contando sobre sua vida e pedindo conselhos sobre sua saúde.

Ainda acerca de "Mi Vestido Cuelga Ahí", Frida gravou toda sua perplexidade diante do capitalismo dos Estados Unidos, que contrastava em demasia com seus valores e com o México vivo, pulsante, natural, colorido e humano que sempre aparecia em suas obras porque constituía sua própria essência, a qual nunca foi abandonada, apesar do tempo vivido em outro país. Essa natureza mexicana é mostrada tanto nas roupas típicas que Frida seguia usando, mesmo na "Gringolândia", quanto em suas pinturas. Aliás, as roupas de estilo indígena aparecerão em outras tantas produções artísticas suas, com variações de cores e tonalidades.

Frida Kahlo teve uma vida intensa. Sorriu, chorou, lamentou-se, sofreu, amou, lutou. Lutou como ninguém por si própria e por seu povo. Também amou como ninguém. Amou a todos que a rodearam. Amou a arte porque ela foi a sua salvação. Um ano após sua única exposição no México enquanto estava viva e alguns dias depois de participar de uma manifestação comunista, faleceu em sua casa, em 13 de julho de 1954. Segundo Herrera (2011), apesar de a certidão de óbito apontar a causa da morte como embolia pulmonar, muitos dizem que foi suicídio devido às pistas que a artista deixou: conversar sobre os atos fúnebres e o conteúdo das últimas páginas de seu diário, nas quais desenhou um anjo provavelmente o anjo da morte - e onde escreveu "Espero alegre la salida - y espero no volver jamás" (KAHLO, 2014, p. 285).

Poucos anos depois de sua morte, a casa onde nasceu, viveu e morreu, a Casa Azul, tornou-se o Museu Frida Kahlo, mantido em quase sua totalidade como na época em que Frida ali viveu, tornando o espaço físico a própria extensão de seu corpo. A maioria dos objetos pessoais da artista, como os vestidos, no entanto, ficaram guardados por muito tempo, visto que só foram encontrados no ano de 2004, no banheiro da Casa Azul, conforme Henestrosa (2012). Após a descoberta, criou-se uma exposição na própria casa, "Las apariencias engañan", para que o público conhecesse de perto as peças que exprimem seu estilo e sua identidade, 


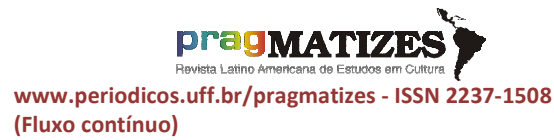

as peças que foram e continuam sendo atratoras de Frida Kahlo.

\section{Frida Kahlo e seus atratores visuais}

Na época em que Frida viveu, no início do século $X X, 0$ conservadorismo nas vestimentas, ao mais puro estilo europeu, herança do colonialismo, predominava em seu país. A pintora mexicana, como sempre mostrou em sua história, não se entregava ao óbvio e, por isso, passou a ousar também em seu estilo, rompendo essa barreira do tradicional. Devido à deformidade em sua perna esquerda, causada pela poliomielite, obrigou-se a usar, desde muito cedo, sapatos com uma pequena plataforma e a adotar calças - incomum às mulheres até então - ou saias longas. E engana-se quem pensa que para ela isso se mostrava um fardo; contrariando as expectativas, "[...] se esmeraba mucho al crear su estilo, de pies a cabeza, adornándose ella misma con las sedas, rebozos, lazos y faldas más espectaculares, siempre acompañados por joyería prehispánica, en plata u oro" (HENESTROSA, 2012, p. 2).

As roupas, assim como as pinturas, as cartas e o diário, atuavam como uma forma de comunicação. Essas escolhas visuais transformavam a mulher fragilizada pela doença, pelo acidente e pelos abortos em alguém forte, magnético - atrator. Ela conhecia seu efeito sedutor e o poder que as vestes tinham - e seguem tendo - de representar quem as usa e fez isso a seu favor. Segundo Henestrosa (2012), quando saía à rua, as crianças perguntavam a ela onde estava o circo; os amigos, por sua vez, questionavam se as peças de estilos, texturas e cores diferentes combinavam. E ela, ignorando tais comentários, até porque sabia que ali residia a sua força e o seu escape dos problemas, seguia arrumando-se primorosamente todos os dias.

Recordando a seção a respeito do percurso de leitores e de leitura, nessa época, em meio à explosão demográfica, à intensificação capitalista e ao surgimento das metrópoles - também mostrada na seção sobre a Revolução Mexicana -, deu-se a transição entre o leitor das formas fixas, o contemplativo, para o leitor das formas dinâmicas, o movente, o qual começava a se acostumar com novos ritmos de atenção. É esse leitor que observa a 
presença das cores, das texturas, das formas atratoras diferenciadas usadas por Frida Kahlo. Seus olhos não estavam acostumados a essa vivacidade, ao dress-code imposto por um bodyscape que impunha uma atitude estética, apesar de todo contexto tradicional; e, por isso, aos poucos, as configurações kahlianas quanto ao estilo de arte e de vestimentas - foram conquistando os leitores de diversas partes do mundo primeiro os estrangeiros, os quais viam na artista um nome para o movimento surrealista.

Porém, sobre essa possível influência do surrealismo, a própria Frida negava com veemência: ela afirmava que pintava o que vinha em sua cabeça, sem considerar mais nada, ainda que suas produções demonstrassem claramente suas peculiaridades surrealistas, conforme destaca Herrera (2011). Talvez isso representasse a ela uma tentativa de mostrar a originalidade de sua arte e, ainda, exercer um possível afastamento das influências estrangeiras, embora Frida soubesse que "o rótulo do surrealismo a ajudaria a conquistar a aclamação da crítica, e ela ficou feliz de ser aceita nos círculos surrealistas" (HERRERA, 2011, p. 309). E foi com esse título, de artista surrealista, dado pelo principal mentor do movimento, e seu amigo particular, André Breton, que ela ficou conhecida por todo o mundo, mesmo que suas escolhas não representassem o universo onírico, abstrato e irreal do movimento, mas a trágica realidade de seus próprios pesadelos reais, aliada ao traço cultural de sua subjetividade, em adesão à estética de um país que se assume como periférico, apesar de centro vivo que alimenta a arte de Kahlo. Dor e nacionalidade, erotismo e cultura, criação e nativismo estão na obra de alguém que não se assume como representante de qualquer movimento que não simbolize as aflições e as alegrias do México vivo.

Ao aplicar uma semiótica espontânea ao próprio corpo, Frida Kahlo assumiu-se portadora de bodyscape. Isso significa que, vivendo no interstício entre as formas tradicionais e fixas, e as formas modernas e flutuantes, já que se mostrava além de seu tempo, a artista transformou-se numa intérprete ativa de sua location, o México das revoluções. Logo, com tais mudanças, ela mesma passou a narrar, por meio 


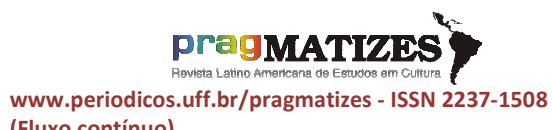
(Fluxo contínuo) de seu corpo e dos cuidados com sua imagem - ainda que seu interior estivesse dilacerado -, "[...] as próprias mudanças comunicacionais e os próprios desejos sensoriais: isto é, é a comunicação, entrelaçada ao consumo e à cultura, que aqui redefine as fisionomias recortadas ao invés da sociedade" (CANEVACCI, 2008, p. 32).

No primeiro casamento com Diego - após o divórcio, ocorrido por solicitação de Diego em 1939, eles se casaram novamente no ano de 1940 (HERRERA, 2011), - Frida Kahlo começou a mostrar sua tendência à valorização da cultura do México tradicional, a principal marca como bodyscape, que cria seu dress-code, assim como também realizou mais uma de suas reprimendas ao colonialismo europeu e às constantes intervenções norte-americanas: casouse vestindo uma tradicional roupa tehuana, a qual pegou emprestada de uma criada indígena (HERRERA, 2011). Nas palavras de Herrera (2011, p. 140), com essa conduta, Frida

[...] estava escolhendo uma nova identidade, o que ela fez com todo o fervor de uma freira que toma o véu. Mesmo em menina, para Frida as roupas eram uma espécie de linguagem, e a partir de seu casamento as intricadas relações entre roupas e autoimagem, e entre estilo pessoal e estilo de pintura, formam uma das tramas secundárias do desenrolar de seu drama.

O referido traje típico mexicano pertence às mulheres do Istmo de Tehuantepec (localizado no sudeste do estado mexicano de Oaxaca), onde vivem em uma sociedade matriarcal, em que elas são responsáveis pelos mercados e pelas questões fiscais, além de possuírem controle sobre os homens (HERRERA, 2011). Ademais, são célebres por sua imponência, sensualidade, astúcia, coragem e força, como, aliás, Frida sempre se mostrou, apesar de não pertencer a essa comunidade - sua mãe era, sim, descendente de indígenas mexicanas, mas seu pai era alemão. O vestido típico tehuano, presença constante nas telas, como apresentado anteriormente, e na vestimenta diária de Frida, de acordo com Herrera (2011, p.140),

era constituído por um blusão bordado e uma saia comprida, geralmente de veludo vermelho ou púrpura, com uma prega de algodão branco na bainha. Os acessórios incluem correntes de ouro e colares de moedas de ouro, que constituem o arduamente conquistado dote das 
moças, em, em ocasiões especiais, um primoroso adorno de cabeça com plissês rendados e engomados, semelhantes a um rufo elisabetano de tamanho fora do comum.

Nesse sentido, 0 vestido tehuano constitui a presença identitária de Frida, o seu dress-code, que escancara a voz polifônica, postura que, como bodyscape, ela assumiu ao fazer suas escolhas para uma vida. $\mathrm{O}$ estilo de Frida não se configurou como uma predileção fugaz, mas algo que de fato sempre a representou. Sua personalidade e suas escolhas destoavam e, analogamente, ecoavam sobre os códigos convencionais, manifestados social e historicamente na location onde estava situada fisicamente, o México tradicional do início do século $X X$ - já que sua mente sempre esteve num além de, como Canevacci (2008) reiterou a respeito do bodyscape. Seu corpo, na época, transformou-se no espaço cultural, como corpo expandido, que buscava mostrar também em suas pinturas; uma fusão de cores e de tradições, um mix de linguagens, a visão de alguém que, por sua história, já não mostrava a preocupação com os olhares rígidos e questionadores de uma sociedade que se penalizava de sua dor. Então, Frida Kahlo decidiu, assim como seus heróis nacionais, revolucionar.

Sua primeira aparição como ícone de estilo ocorreu na revista Vogue em outubro de 1937, como Henestrosa (2012, p. 2) registra:

Fue cuando la visionaria directora de la revista, Edna Woolman (desde1914 hasta 1952), la retrató por primera vez en sus páginas. Por medio de su lente, Toni Frissell inmortalizó la imagen de la mujer que se convertiría en una de las artistas más emblemáticas del siglo XX. Obsesionada con la dimensión visual de sí misma, ya antes de su primera exhibición individual Kahlo captó la atención de las revistas de moda con de su personalidad y su arte, como lo ha hecho en los últimos 75 años, inspirando desde entonces a tantos diseñadores.

Ainda segundo Henestrosa (2012), em seguida, vieram outros reconhecedores de seu fazer-se arte, como André Breton e a exposição "Mexique", em Paris, no ano de 1939, com a presença da própria Frida. De acordó com Henestrosa (2012, p. 2), "su vestido étnico tehuano causó tanta sensación entre las élites europeas que se dice que la diseñadora estrella de aquel entonces, Elsa Schiaparelli, creó un vestido llamado La Robe Madame Rivera (el vestido Madame 


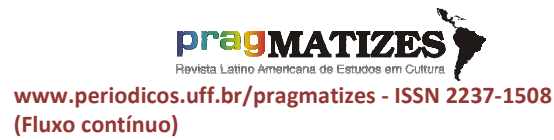

Rivera), en su honor".Após sua morte, Frida seguiu influenciando os artistas da moda, a exemplo de Jean Paul Gaultier e Christian Lacroix, que em sua coleção primavera-verão, em 1998, homenagearam a pintora mexicana. Posteriormente, foi a vez de Kris Van Assche, no outono de 2002; no ano de 2005, os estilistas britânicos Clements Riveiro e Temperly London também se renderam ao seu universo surreal. Tao Kurhara, em 2009, exibiu bonecas escandinavas com referências a Frida; em 2012, Rei Kawakubo - mestre de Tao Kurhara apresentou sua coleção White Drama ("Drama Branco"), na qual "a través del color y materiales como satén y encaje blanco, llevó al espectador en un viaje hacia el universo de Frida", como salienta Henestrosa (2012, p. 3).

Com isso, como um eu-narrador e por meio de uma maior exposição midiática, pela qual o filme "Frida" produzido em 2002 por Julie Taymo e inspirado na obra Frida: a biografia, de Hayden Herrera (2011) - também foi responsável, a artista chegou aos olhos e aos ouvidos, como um sounddesign (CANEVACCI, 2008), dos novos leitores que começavam a aparecer, atraídos pelas escolhas magnéticas de Frida. $\mathrm{O}$ primeiro a ser conquistado, quando a web começava a constituir parte das rotinas de uma maior parte da sociedade, foi 0 imersivo, que navegando na internet, começou a adentrar no universo virtual e a (re)encontrar Frida Kahlo. Esse foi o momento em que a Fridomania, como nominou Henestrosa (2012), começou a alçar voo, principalmente quando, em 2004, o guarda-roupa de Frida foi descoberto no banheiro da Casa Azul e, hoje, os objetos pessoais, como roupas e acessórios, compõem a exposição "Las apariencias engañan", nessa mesma casa.

Com a ascensão das redes sociais e o fácil acesso aos aparelhos móveis, os smartphones, outro leitor começou a acompanhar e a divulgar o universo de Frida Kahlo. O leitor ubíquo, ao ser atraído por aquela imagem intrigante e atratora, por uma sobrancelha única, flores adornando os cabelos negros, cores e tecidos extravagantes, além de uma história forte, comovente e inspiradora, adjetivos que sempre acompanharão Frida Kahlo, não apenas contempla e aprofunda seus conhecimentos sobre 


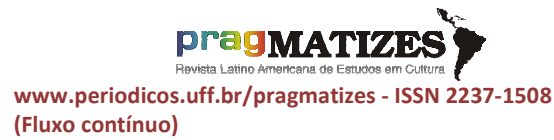
(Fluxo contínuo) ela, como se torna alguém que efetivamente participa dessa história.

É o leitor que compartilha suas produções. É o leitor que se inspira em sua caminhada como personagem real. Nesse contexto, as célebres frases de Frida Kahlo, escritas principalmente em seu diário e nas cartas destinadas aos seus muitos amigos, insuflam, sobremodo, mulheres leitoras que possam se sentir fracas, tristes ou desamparadas. Muitas citações de Frida ajudam a fortalecer e dar coragem àquelas que precisam lutar, diariamente, contra a violência, o preconceito e a desvalorização. As publicações nas redes sociais, como no Instagram, por exemplo, conferem significação, ganham expressividade e dão voz àqueles leitores que antes se apresentavam como meros ouvintesespectadores. Em uma pesquisa rápida na rede social, ao digitar 0 nome "Frida", numerosos perfis e hashtags aparecem na tela, com intuito comercial ou não. Entre os nãocomerciais, estão, por exemplo, os perfis "Filhas de Frida", "Todas Frida", "Frida Feminista", entre outros, que divulgam as frases mais famosas de Frida Kahlo, bem como outras publicações com frases motivacionais de autorias diversas e/ou relatos de experiências próprias ou de outrem.

Assim, de bodyscape, como alguém que fez uso de um dress-code intuitivo, um corpo semiótico que atraiu e segue atraindo, marcado em uma location historicamente em luta, Frida passou a ser um ícone pop altamente consumido. Nesse momento, com essa versão insigne da artista, emerge - leitor óptico, não relacionado por Santaella quanto a seus perfis leitores, mas apresentado por Canevacci (2008). Neste artigo, ressignificamos o conceito de Canevacci sobre esse leitor; o autor não especifica que ele se apresenta como ser humano, mas suas considerações deixam em aberto essa possibilidade interpretativa. Em seu texto, Canevacci (2008, p. 96) afirma:

Então, o código de barras é um formidável indicador para entender o trânsito da cidade industrial para a metrópole comunicacional. É a carta de identidade da mercadoria, o seu nome e sobrenome, a sua residência, a idade, a cor, o tamanho. É o valor agregado informacional que assume a mercadoria no ato de ser vista por um leitor óptico que transforma os dados não apenas e não tanto em preço. $\mathrm{O}$ ato decisivo é bem mais complexo em tempo real [...]. 
O universo de Frida Kahlo, sua história, suas pinturas, suas produções escritas - cartas, bilhetes e diário -, sua casa, sua vida, atualmente, no desenrolar do século XXI, na era do consumo desenfreado, está sendo consumido por leitores ópticos como uma mercadoria num contexto fetichista perverso. Esses leitores não se contentam em admirar, como o leitor contemplativo; a conhecer pela rede comunicacional, como o leitor imersivo; ou a socializar, como o leitor ubíquo. Ele precisa consumir. Portanto, consome diferentes "produtos", desde objetos, como canecas, chaveiros, quadros e almofadas, até a própria vida de Frida Kahlo, como acontece com outras personagens, reais ou fictícias. Isso se torna perceptível quando se nota o número de pessoas que compram os produtos que estampam sua figura, que se vestem como a artista em diversas situações, principalmente em festas e em ensaios fotográficos, ou que passam a viver conforme seu estilo. Uma breve pesquisa nas redes sociais revela o quanto esses leitores visuais - ópticos - sentem-se orgulhosos em mostrarem-se fãs da artista, mesmo que, talvez, desconheçam sua verdadeira história ou extrapolem os limites da admiração ao assumir-se como Frida, uma persona criada por uma lógica consumista transgressora.

Porém, apesar dessa dicotômica realidade, que contrasta em demasia com suas concepções socialistas, Frida, como sempre desejou, marcou-se como um bodyscape ultra-passante, usando as denominações de Canevacci (2008). Nunca se entregou aos problemas, às fraturas que constantemente lhe tiravam do prumo. Ao contrário, amou, lutou e ultrapassou os tempos. Chegou ao século $X X I$ como alguém que merece ser lembrado por sua força e por sua atitude estética que atraiu e que segue atraindo olhares, como um imã que nunca perde sua energia, como um olhar que vê quando é visto, e que consome quando é consumido.

\section{Considerações finais}

No início deste artigo, expusemos os principais objetivos que buscávamos com o estudo sobre os atratores de Frida: apresentar um recorte sobre o contexto históricosocial, a vida e a obra da artista mexicana Frida Kahlo, assim como 


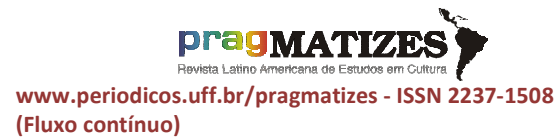
(Fluxo contínuo) realizar uma análise dos elementos visuais que atraíram diferentes leitores a partir de uma perspectiva teórica diferente da fortuna crítica que ora se apresenta sobre a pintora. Devido à natureza do estudo, um artigo de caráter acadêmico, as ideias que aqui oferecemos apenas sinalizam todo 0 potencial que a pesquisa oferece; portanto, esperamos que o leitor que se identifica com o tema não se frustre pelo fato de não encontrar o aprofundamento que, talvez, esperasse. A intenção foi justamente de provocar leituras que podem ser inéditas a quem se interesse pela produção e pela própria personalidade de Frida Kahlo, a menina que, ao tornar-se mulher, da pior maneira, redescobriu-se e atraiu os olhares de todas as partes do mundo.

Muito provavelmente, a pintora mexicana foi uma das únicas personalidades que alcançou tamanho sucesso e com tantos perfis de leitores. O leitor movente, durante o século $X X$, sentia um estranhamento e, concomitantemente, uma curiosidade em relação às condutas semióticas do bodyscape que Frida Kahlo se tornou ao criar seu dresscode numa época em que a location se mostrava séria e tradicional; já os leitores imersivos e ubíquos, na transição entre os séculos $X X$ e XXI, passaram a sentir admiração pela mulher que transcendeu seu tempo e seu espaço.Por sua vez, ao unir todas as caraterísticas dos leitores anteriores, o leitor óptico observa, admira e consome em uma perspectiva altamente fetichista; e, ao assumir essa postura, traçou uma lógica de consumo pelo olhar que é seduzido. Para esse leitor, não basta conhecer, é preciso consumir Frida Kahlo. De certa forma, o olhar que quer consumir se perde no interstício de uma coisa jamais conquistada, já que é sedutora e poderosa ao extremo. Frida é um sujeito mesmo quando se objetiva; é uma mulher, mesmo que inanimada em uma boneca; é uma pele que se marca pelo vestuário e paramenta todos os itens que a cultura industrial do entretenimento pensa produzir para venda. Mas não há venda, há uma troca entre corpos. Há um câmbio amoroso, em um êxtase de sentidos atraídos.

Enfim, Frida Kahlo teve o corpo fraturado e fragilizado, mas confirmou sua existência pelas escolhas que fez, 
pelas pinturas que realizou, pela moda criou. Com o passar do tempo, teve o corpo culturalmente expandido e plasmado, como uma moldura, nas diversas recriações que ecoaram pelas mãos de outros artistas. Porém, alcançou efetivamente ressignificações em meio à cultura digital, no século XXI. Traçou, como ninguém, uma revolução dos códigos e uma revolução leitora que ainda não findou; muito pelo contrário, a história do México e a história de Frida -que se interligam em diferentes aspectos mostram o potencial que têm, um caminho que outros pesquisadores ainda podem seguir como uma inesgotável fonte de observação, de descobertas e redescobertas. ¡Viva Frida Kahlo!

\section{Referências bibliográficas}

CANEVACCI, Massimo. Fetichismos visuais: corpos erópticos e metrópole comunicacional. São Paulo: Ateliê Editorial, 2008.

FERNÁNDEZ, Iñigo. Historia de Mexico: un recorrido desde los tiempos prehistóricos hasta la época actual. Ciudad de México: Monclem Ediciones, 2002.

FERREIRA, Aurélio Buarque de Holanda. Mini Aurélio: o dicionário da língua portuguesa. Curitiba: Positivo, 2010
FLORENCIO, Sergio. Os mexicanos. São Paulo: Contexto, 2014.

FRIDA. Diretora: Julie Taymo. Canadá/México/Estados Unidos: Miramax Films, 2002. 1 DVD. 123min.

FUENTES, Carlos. Introducción. In: KAHLO, Frida. El Diario de Frida Kahlo: un íntimo autorretrato. Hong Kong: Midas Printing, 2014. p. 7-30.

HENESTROSA, Circe. Trasciende su legado más moderno. Museo Frida Kahlo. Ciudad de México, 2012. Disponível em: https://www.museofridakahlo.org.mx/w p-content/uploads/2020/12/LasApariencias-Engan\%CC\%83an.pdf. Acesso em: 20 jan. 2021.

HERRERA, Hayden. Frida: a biografia. São Paulo: Biblioteca Azul, 2011.

KAHLO, Frida. El Diario de Frida Kahlo: un íntimo autorretrato. Hong Kong: Midas Printing, 2014.

KETTENMANN, Andrea. Frida Kahlo1907-1954: dor e paixão. Slovakia: Taschen, 2015.

PRODANOV, Cleber Cristiano; FREITAS, Ernani Cesar de. Metodologia do trabalho científico: métodos e técnicas da pesquisa e do trabalho acadêmico. Novo Hamburgo: Feevale, 2013.

SANTAELLA, Lucia. Comunicação ubíqua: repercussões na cultura e na educação. São Paulo: Paulus, 2013.

SANTAELLA, Lucia. Navegar no ciberespaço: o perfil cognitivo do leitor imersivo. São Paulo: Paulus, 2004.

ZAMORA, Martha. Frida: el pincel de la angustia. Ciudad de México: La Herradura, 2007. 